\title{
COVID-19 and online education: Digital inequality and other dilemmas of rural students in accessing online education during the pandemic
}

\author{
Malini Srinivasan \\ Jishnu D. \\ Shamala R. ${ }^{1}$ \\ Central University of Tamil Nadu, India
}

To cite this article: Srinivasan, M., Jishnu D., \& Shamala R. (2021). COVID-19 and online education: Digital inequality and other dilemmas of rural students in accessing online education during the pandemic. World of Media. Journal of Russian Media and Journalism Studies 4: 34-54. DOI: 10.30547/worldofmedia.4.2021.2

\section{Abstract}

It is widely assumed among academicians that the COVID-19 pandemic has negative implications for the education of school students. However, institutions tried to balance that limitation by using online education, and there exist some inequalities among students. Most of the studies conducted during COVID-19 on online education focused on urban school students and their access to online education. In particular, rural school students and their online education remain an open question. Twenty in-depth interviews with rural student respondents determine the fundamental problems and challenge the rural school students' face in online education during the COVID-19 pandemic lockdown. The study identifies six major problems of rural students: inadequate technology, unacquainted academic atmosphere, digital disconnect, physical well-being, the distractions inherent with the medium, and digital illiteracy. The identified constraints draw inferences to a critical concept in online learning that is digital inequality. Digital inequality refers to the disparity in the access, distribution of technology, information because of various socio-economic and cultural factors.

The study also discusses the suggestions of rural students regarding the betterment of online education. The recommendations from the rural students include providing appropriate technological infrastructure, facilitating technical

\footnotetext{
${ }^{1}$ Corresponding author:

Shamala R., Central University of Tamil Nadu, Thiruvarur, CUTN Bridge, Neelakudy, Tamil Nadu 610005, India.

Email: shamala@cutn.ac.in
} 
assistance and providing a convenient academic atmosphere. The suggestions are pointing towards the idea of digital inclusion that is vital in online education. Digital inclusion is defined as the ability of individuals or groups of people to access and use information and communication technologies. It is not only about access in a broader sense the opportunities of using innovative hardware and software technology, content and services, getting proper digital literacy pieces of training and the effective use of these services. The findings of the study will help to bridge the disparities in online education. These findings will help the academic community to identify the needs of rural children. It will help build infrastructure for online learning and give extensive support to the school children of rural communities. These findings are also vital for the communication scholars as the disparity in the distribution of information and knowledge is a prime concern for them.

\section{Keywords}

COVID-19, online education, rural students, problems, solutions, digital inequality, digital inclusion.

\section{Introduction}

COVID-19 has negatively influenced all sorts of human life (Jena, 2020). Education is one of the most affected areas. Due to the pandemic, schools, colleges and universities are closed for an indefinite period (Mishra, 2020). The present situation of COVID-19 has worsened the inequalities in education all around the world. This COVID-19 pandemic adversely impacted over 290 million students across the 22 Asian countries due to the closure of schools (Muthuprasad et al., 2020). An estimate of 1.59 billion students is facing an education gap due to COVID-19. It has forced educational institutions across India to shift to online learning. Online learning is defined as an instructive method propagated to students through the internet, using computers, laptops and mobile phones, etc. (Singh \& Thurman, 2019). Even though many scholars opinionated that online classes cannot substitute classroom learning (Kumar, 2020). For example, Pumptow and Brah (2020) studied the inadequacy of online education in students' academic achievement. Yet, we quickly adjust and adapt to the new way of online learning. But this sudden shift from classroom learning to online learning has created confusion among the teachers and students. De la Varre, Irvin, Jordan, Hannum and Farmer (2014) studied the various puzzles of online education that led to the dropout of K12 students in rural USA. The study identified scheduling and time constraints, academic rigor 
and motivation, technology problems, problems with the online medium, lack of teacher immediacy and parental influences as the primary reasons for dropout. Lembani, Gunter, Breines and Dalu (2020) study the geographical limitations to access to technology and accessing online education. The study's findings implied that students from urban areas have better educational experience than students in rural areas. The study also points out the lack of access to technology among rural students. Besides, the digital divide between urban and rural students is discussed in the study. Mahmood S. (2021) examined the strategies for online education during the COVID-19 pandemic. The study suggested making collaborations with telecommunication industries for a better online experience, flexible teaching and assessment policies, recording online lectures and facilitating technical support as the strategies to be followed in online education during the COVID-19. Adedoyin and Soykan (2020) examined the challenges of online learning during the pandemic. They have categorised challenges as technological, socio-economic, digital competence, heavy workload and compatibility.

School students in rural India are primal to the digital education scenario. Moreover, many rural parents are not aware of the concept of online education and facilitate it. Rural students face so many problems relating to geography, education, and technology (de la Varre et al., 2014). Besides, there are high chances of disparities between the privileged, affluent students and the deprived rural students. Students, especially those from a poor socio-economic background in India, face a considerable amount of stress relating to online education. All these factors are pointing towards the problem of digital inequality.

Digital inequality is an economic and social inequality concerned with the access, use and impact of modern ICT's. It can be seen in macro-level between countries, the developed and underdeveloped and micro-level in between the students of the same class. There are various determinants of the digital inequalities, namely infrastructure, digital skills, geographic location and economic stability ('The digital divide - information, people, and technology,' n.d.).

There are multiple student suicides after failing to cope with online classes in Tamil Nadu ${ }^{2}$. It is vital to address the issue of student suicides occurring in rural areas. The basic right of students - right to education - cannot be hampered

${ }^{2}$ EMMANUEL, G. (2020). Tamil Nadu: 14-year-old dies by suicide after father could not buy smartphone for online classes. Bangalore Mirror, $1^{\text {st }}$ August, 2020. Available from: https://bangaloremirror.indiatimes.com/news/india/tamil-nadu14-year-old-dies-by-suicide-after-father-could-not-buy-smartphone-for-onlineclasses/articleshow/77303306.cms 
due to inadequate infrastructure and ill-conceived implementation of online education. In the pilot study, we identified that rural students have modest facilities for their online education. Most rural students can be seen as a digital underclass as they are first-time users of the internet.

The digital underclass is a disadvantaged section of society that faces many difficulties in making connections with the digital world. Rural students' problems in online education must be resolved. Government and other NGOs should help rural children to achieve their basic right to education. In this regard, through qualitative in-depth interviews with high school and higher secondary school children of Thiruvarur, one of the most backward districts of Tamil Nadu, we tried to find out the real problems faced by rural students in online education and their proposed solutions for the issues. The study's findings will help to understand the difficulties of rural children, especially high school and higher secondary students, their expectations from online education and their suggestions regarding the betterment of online education. The answers to these vital questions will be instrumental to the education policymakers, academic experts, and teachers to devise suitable educational techniques suitable for rural students' needs.

$R Q 1$. What problems are rural students facing in online education?

$R Q 2$. What are the suggestions of rural students for the betterment of online education?

\section{Literature review}

Digital divide is a buzz word used to explain the social implications of discrepancies in access to ICT between socioeconomic groups and to the achievement of the necessary skill set (Cronin, 2002). Gaillard (2001) asserted that the digital divide is the line that separates those who have computer access, along with corresponding skills and use the internet, from those who neither have access to computer technology nor the internet. The term digital inequality refers to the disparities in accessing knowledge and skills of using digital technologies between various groups or within groups. It is evident among developed and underdeveloped countries, poor and rich, rural and urban, young and old, etc. (Miroshnichenko, Morozova, \& Meshcheryakova, 2021). Numerous studies have focused on the digital inequalities during the COVID-19 pandemic lockdowns (Nguyen, Hargittai, \& Marler, 2021). Online education is considered one of the most concerning areas relating to digital inequalities. COVID-19 lockdowns have forced the digitisation of education which in turn increases the digital inequalities among the students (González-Betancor, López-Puig, \& Cardenal, 2021) 
Aboagye et al. (2020) study states that the learners' intention to study via online showed that the students were not ready to study via online means. Koh et al. (2020) findings suggest that students' current experiences in online education influences their desire to use e-learning systems. In order to encourage student-centered digital learning experience, upgradation of technological features and faculty preparation have to be considered.

The implementation of online education during COVID-19 pandemic has altered the teaching-learning process widely across the country. There were lots of difficulties in adapting online education. Volery and Lord (2000) argued that the lecturer plays a central role in online education, because their effort and contribution become the learning catalyst and act as a knowledge navigator. E-learning is gradually becoming more used in universities to enhance the teaching and learning process more effectively. It predominantly requires instructors' contribution to design a motivating e-learning environment to engage students actively in their learning and boost motivation.

Almazova et al. (2020) elaborated the challenges faced by university faculty members in teaching via online education. They are a computer literacy level, technological infrastructure of the university, readiness of the students and academic staff for online learning. The teaching methods and techniques adopted by the faculty differ from traditional teaching methods to digital teaching methods. The teacher's support is more important for the student to adapt for the online learning environment and it also ensures efficient online education.

In the era of technological advancement, digital literacy is very important as its implication prevails in all the sectors. Zulkarnain et al. (2020) findings illustrated the importance of digital literacy as it has a high impact on knowledge gaining, understanding and using media. During the pandemic, social media was adopted widely for dissemination of information for the public as well as for the student communities. The students used social media for interaction with their peers and academicians. Vishkaie (2020) asserted that power of digital technology can be utilised for educational purposes, but it needs intensive training and qualified staff, only then the technologies can be promoted to make the best use of it. Only with digital literacy can we acquire additional resources. The knowledge of digital literacy is more important in the future for an inclusive, collaborative and sustainable environment.

Though the communication technology has evolved to a very great extent, still it is not accessed by all. The geographical, economic and social factors are paving the way for digital divide. There are various other factors underlying the 
cause of the digital divide. There is a huge gap between the rural and urban areas in accessing the resources. Mpungose (2020) states that Short Message Service (SMS) bridges the digital divide, because of the affordable network packages. Students have adopted SMS for interactive and collaborative learning, it also gives them personal and social experience in knowledge acquisition. Gaurav (2020) results indicated rural-urban disparity plays a major role in digital divide. Inclusive educational policy has to be implemented to eradicate the digital divide.

Aydin (2020) asserted that curricula are school syllabus for developing computer skills, but still the digital divide exists with various socio-demographic characteristics. Aswathi and Mohamed Haneefa K. (2020) illustrated that attitude towards information technology, digital competence and frequency of internet use play a significant role in the prevalence of digital divide. The unequal access to the use of information and communication technologies is termed as digital exclusion. This exclusion will hinder them from participation in society. There are various reasons for digital exclusion, like affordability, technological infrastructure, gender gap, etc. Ullah (2020) study shows that the elite community enjoy the privilege of accessing the information and communication technologies, whereas the poorer groups have very limited access to the digital services and they are deprived from their participation in the society.

Raza et al. (2020) asserted a few issues faced by students in the overall learning experience through online education. They are the following: absence of physical presence of the faculty members, lack in student-teacher relationship, lack of satisfaction in learning process and perceived learning. Tartavulea et al. (2020) states that the adoption of e-learning processes by students and academic institutions was high, and they used synchronous and asynchronous assessment and interaction methods. It led to the passive delivery of lectures, and it has reduced the interaction between the student and the teacher.

The dynamics of digital literacy and its actual application to everyday life education, work, leisure, politics, social engagement - that is closely related to education, especially when we focus on higher education and lifelong learning. Exposure to information and communication technologies are changing the way students learn, how they are engaged and their attitudes (Prensky, 2001a; 2001b; 2005). Reinforcing only physical access to ICT will not help in bridging the digital divide, rather required digital skills have to be imparted in order to reduce the digital divide gap. The digital divide in education is not a matter of physical access but a matter of digital skills and how competent students 
(and teachers) are at computer and internet usage (Peña-López, 2010). Carvin (2000), Hargittai (2002), Warschauer (2004) research illustrated the crucial importance of digital competencies. It is the key factor between infrastructures (hardware, software and connectivity) and their expected output and impact (digital content and services, and effective usage for specific purposes).

Pearson (2002) emphasised the importance of usability in the digital divide. Providing public access to the internet gives definite groups the opportunity to advance by providing them with the required technical skill set which are needed to compete in the digital economy. Peña-López (2010) mentioned that beyond attitudes, there is a whole constellation of strategic digital competences that are most needed. Only with the help of digital competencies, the mix of ICTs in education can have an impact, both in terms of digital literacy and in terms of academic performance.

Gladkova et al. (2020) study states that ethnicity plays a major role in defining the digital capital. People belonging to the ethnic majority of the respective country and those living in metropolitan or cosmopolitan cities tend to have a higher level of digital capital. The study mentioned that ethnicity solely does not define the level of users' digital capital, but it still remains an important and understudied issue. Bamezai et al. (2020) findings suggested that epistemological and ontological perspectives in teaching and research programmes remain insufficient in maintaining a consistent gendered approach and are universally sporadic. The study also states that mapping of gender mainstreaming in journalism education would hold a promise of ushering in affirmative policies and actions in changing the media discourse pertaining to exploitation, disempowerment and marginalisation of women. Vartanova et al. (2021) findings mentioned the difficulties in converting analogue content into digital form. The study stated that it is important to understand the competencies of the journalistic community within the analogue and digital generations, which are in demand in the production of content in 'digital form.' Many experts in this field recognise the need to adapt the analogy generation of journalists to work in the digital information environment, where the complexity of the transformation of journalists' competencies is concretized, summarized and analysed in the project.

Pearson (2002) study states that those who have access to technology are being offered more opportunities than ever before. On the other hand, those who cannot afford or use the ICT tools are restricted from participating in the digital world. Cronin (2002) illustrated that access to computers and the internet, and the facility to effectively make use of this technology, are becoming increasingly 
important for full participation in social, political and economic life. Access to digital technologies is essential for ensuring equity in access to the information economy, for enabling governments to achieve e-service delivery objectives, and for allowing people to capitalize on the opportunities for economic growth offered by the information age.

Van Deursen et al. (2019) research emphasised other scholars' conclusions. Many scholars of the second-level digital divide have concluded that the divides in internet skills and type of use continue to expand even after physical access is universal. That study finding - indicates that the first-level digital divide remains a problem in one of the richest and most technologically advanced countries in the world. By extending basic physical access combined with material access, the study finds that a diversity in access to devices and peripherals, device-related opportunities, and the ongoing expenses required to maintain the hardware, software, and subscriptions affect existing inequalities related to internet skills, uses, and outcomes. Ragnedda (2018) asserted that those who do not access the internet (first level of digital divide), or do not use it 'effectively' (second level of digital divide), or are not able to transform the online experience into something concrete and tangible (third level of digital divide), lose noteworthy opportunities in the economic, political, cultural, personal, and social spheres. By contrast, those who access the internet, have elaborated a high level of digital capital and use the internet in an 'effective' and 'productive' way, tend to broaden their opportunities, improving the quality of their life and reinforce personal position in society, their wellbeing and their general quality of life.

Nieminen (2016) illustrated that economic emphasis linked to digital information and communication technologies will widen the digital divide, which in turn will potentially sharpen social inequalities in the global scale. The study also clearly mentioned that technology as such is not causing the social problem within the digital communications technology, but the problem is in the ways how it has been applied, reflecting unequal power relations in our societies. Tarman (2003) mentioned that the digital divide is a social problem which is caused by inequalities in the ability to access and to use ICT tools. The digital divide is a threat to social and economic justice as well as to education. Selwyn et al. (2001) stated that to curb the existing digital divide gap, the greatest possible changes could be in the institutional barriers to participation, lack of appropriate opportunities locally, including the current lack of flexibility in courses, lack of credit for informal prior learning, poor guidance, and lack of basic skills. Istance and Rees (1995) study asserted that interrupted patterns of participation would lead to high non completion rates. Trappel (2019) stated that inequalities are the 
unwanted companions of media and communication. Although the digital divide is often seen as an individual problem, it undoubtedly requires collective solutions (Selwyn et al., 2007).

Research objectives

The prime objective of the study is to find out the problems of rural school students in online education as well as their proposed solutions for the issues.

The specific objectives are:

- To find out the problems rural students are facing in online education.

- To know about the suggestions of rural students for the betterment of online education.

\section{Research methodology}

To analyse the objectives, the research paper uses a qualitative research approach. In-depth interviews (IDIs) with semi-structured questionnaires (all open-ended questions) were used to collect primary data from 20 rural students attending online classes. Through the open-ended questions, the issues, challenges and problems of the rural school students faced while online education during the pandemic can be analysed. The respondents were between the age group of 14-17. All the respondents were chosen from the Thiruvarur district of Tamil Nadu, India. Of the total, 13 respondents were female and 7 were male. They are high school and higher secondary school students. The in-depth interviews of the respondents were audio-recorded, transcribed from the Tamil language to English, and later used grounded theory (Glaser \& Strauss, 1967) to analyse the data. The researcher first conducted open coding - marking several categories that developed from participants' words, which were later classified into more specific categories and themes - and in vivo coding - in this, the researcher noted the participants' comments that are indicative of the language of users. The researcher engaged in axial coding in the next step by collapsing the open codes into relevant subcategories (Strauss \& Corbin, 1998). The final coding process was selective coding, in which the researcher refined the categories to produce theories and central themes that are formed and explained the data (Cresswell, 2013; Strauss \& Corbin, 1998).

\section{Theoretical framework}

Researchers have focused on the challenges and opportunities of online education during the COVID-19 pandemic (Adedoyin \& Soykan, 2020). However, most of the research is conducted on the higher education sector in an urban setting. Thus, there are comparatively fewer chances of studying digital inequalities. Our 
study, on the contrary, examines in-depth the digital inequalities faced by rural high school and higher secondary school students. The scope of our research is further supplemented as our sample was from Thiruvarur, one of the most rural districts in Tamil Nadu state in South India. Studying the digital inequalities among the school students in the rural setting is vital as the extensive magnitude of the problem insists on a comprehensive insight of the problem and significant research in the areas concerned.

\section{Data analysis and interpretation}

Table 1

\section{Participant's demographic information}

\begin{tabular}{|l|c|c|c|c|}
\hline Student Number & Age & Gender & Class & $\begin{array}{c}\text { Length of the interview } \\
\text { (MINS) }\end{array}$ \\
\hline Student 1 & 15 & Male & VII & 30.21 \\
\hline Student 2 & 17 & Female & IX & 10.25 \\
\hline Student 3 & 16 & Male & X & 15.00 \\
\hline Student 4 & 14 & Female & XI & 14.30 \\
\hline Student 5 & 15 & Male & XII & 18.35 \\
\hline Student 6 & 15 & Female & XI & 20.05 \\
\hline Student 7 & 14 & Female & X & 24.08 \\
\hline Student 8 & 17 & Male & XI & 10.36 \\
\hline Student 9 & 17 & Female & X & 09.32 \\
\hline Student 10 & 16 & Female & IX & 14.05 \\
\hline Student 11 & 16 & Female & X & 18.30 \\
\hline Student 12 & 15 & Male & XII & 25.02 \\
\hline Student 13 & 14 & Female & X & 08.02 \\
\hline Student 14 & 15 & Female & X & 09.58 \\
\hline Student 15 & 16 & Female & XII & 24.05 \\
\hline Student 16 & 17 & Male & X & 29.12 \\
\hline Student 17 & 14 & Female & XII & 24.21 \\
\hline Student 18 & 16 & Female & X & 25.47 \\
\hline Student 19 & 14 & Male & X & 24.12 \\
\hline Student 20 & 15 & Female & XII & 09.02 \\
\hline
\end{tabular}


After carefully reading and understanding the interview transcripts, the researcher employed the coding process, and the following themes have emerged for getting a notion of each research question. Through an open coding procedure, the study identifies the problems, issues and challenges faced by rural school students while attending online education. Then the responses based on the themes were grouped and presented below. The main challenges identified by the researchers are lack of adequate technology, lack of academic atmosphere, the issue with the novelty of the medium, health issues, internet distraction and lack of digital literacy.

RQ 1: Problems faced by rural students in online education.

Interviewees discussed six problems they are facing in attending online education.

\section{Inadequate technology}

This theme delineates issues like poor internet, no power back up, the problem with range, issues with devices, content clarity issues, lack of availability. All the participants reported at least one of these issues during the conversion.

Narratives such as

'I miss the classes due to the poor internet connection. The bandwidth is not proper in my locality. When I attend classes, the video content keeps on buffering for a very long time. Due to an inadequate internet connection, I cannot attend the online lecture continuously. When I miss a lecture, it is difficult for me to cope with the content and syllabus taught in the lecture' (Students 1, 5, 8, 10, 11 and 19 expressed).

The lack of adequate devices is the next issue. Though the students have an internet connection, the incapacity of the devices hinders online education. The disruption in the devices also makes students miss their lectures.

'My device got hung up. I have an adequate internet connection in my locality. I use my parents' mobile for accessing online education. The smartphone they own is a very basic model, and it is very old. It does not have the required capacity to access my online classes. When I try to use the mobile continuously, it gets hung up and it will be very difficult for me' (Students 3, 9 and 10 highlighted).

The next issue is also related to the problem of the device, which hinders the rural students from attending the online lectures.

'They have online classes daily. I attend online classes through my mother's mobile. The phone battery usually exhausts during online class hours. The online classes are conducted continuously in daytime for a minimum of four to five hours. There would be very little break time. After attending online lectures, teachers would give assignments and tests, and we are monitored daily. I use the same 
mobile for attending online lectures, for doing homework and assignments. The battery capacity is not enough for me to attend class and do homework. So, I have to keep the mobile for charging in regular intervals to attend lectures. If the battery gets low during my class hours, I have to skip the lecture to get the mobile charged' (Students 4, 8 and 15 shared the problems). Student 7 reported the additional challenge in attending online education through inadequate devices. The interrupted power supply makes it even more difficult for students to participate in online classes. 'In my locality, there is an interrupted power supply most of the time. Due to which I cannot attend my online class properly. The mobile that I use to attend online lectures has poor battery capacity. If there is an interrupted power supply, then it doubles the problem in attending online lectures.'

The next challenge in attending online education is video and audio clarity, which in turn result in a lack of content clarity. Student 20 says:

'I can't see the video content properly. At times the audio clarity is also not good. For maths and science, I find it difficult to attend an online class. My teacher owns a blackboard in her house. She solves the sums on the blackboard in the online lecture. But the video clarity will not be good. Understanding the algorithms of the solution would be very difficult. She has to explain every time very slowly; only then we can follow up. It consumes a lot of time to understand a single concept or theory. We find it difficult to cover the syllabus on time. The same goes for the science subject. When attending lectures in schools, we have practical sessions, through which we learn the concept and working of certain equipment. It was easy for us in offline education. For subjects like biology, teachers do not have to model human organs. So understanding the mechanism of each body part is very difficult.'

The next challenge in attending online education, as stated by Student 6, is connected with the lack of availability of devices in her home for online education.

'I have two siblings. All three of us are attending online education. But we have only one mobile phone to attend the lecture. All our classes are scheduled only during the day hours. If my sister has an online class, then my brother and I have to miss the lecture. If one is attending the lecture, then the other two of us have to miss our lectures. Due to this, we lack consistency in understanding the concept, coping with the syllabus and we also fail to submit our assignments and tests on time. I'm finding it very difficult to attend the online classes.'

\section{Unacquainted academic atmosphere}

This theme discusses concerns like physical noise, family chores that would affect the online education process. The shift from classroom learning to home causes these constraints. The majority of the participants reported these issues. 
'I live in a joint family. I have siblings at home, and they are less than five years old. When I'm attending online classes, they play happily. They make a lot of noise when playing. Due to the pandemic, our parents will not allow them to go out of the home, so they will be playing inside the home. Their noise distracts me, and I can't concentrate while others are playing' (Students 16 and 17 mentioned). 'We are in a joint family pattern. People in the house will be watching television, or they will be talking with one another. In that case, I cannot hear or listen to the online lecture properly' (Students 2, 9, 15 shared). 'When I'm attending online lectures, my family members will call me to help them with the household chores. They don't understand the importance of online education. I miss my lectures, and it would be difficult for me to take from my teachers for these reasons' (Students 5, 8, and 18 said). Student 19 expresses his concern about studying on the balcony for getting a better mobile network where the vehicle noise-causing trouble for his concentration. 'My locality has a poor internet connection, so I use to sit in my balcony to attend lectures, where I get proper network bandwidth.' Student 9 expresses her concern about taking care of her small baby sister while attending online education as her parents are working labourers. 'My parents are daily wage workers. During the pandemic, they lost their job. So they started selling vegetables. My sister is two years old, as my parents have to go to work daily, I babysit. I cannot attend the lectures regularly.'

\section{Digital disconnect}

This theme takes up obstacles like lack of peer discussion, inability to grasp concepts, difficulty to clarify doubts, difficulty in real-time interaction. Most of the participants reported the above issues which have occurred due to the novelty of the medium and the participants are not used to it.

Narratives like 'I can't understand some concepts in online lectures, due to the technical error and other challenges in accessing online education' (Students 3, 7 and 10 mentioned). 'I cannot clarify doubts in online lectures. Raising questions and clarifying the doubts with the teachers is closely impossible. Many of us would ask a question at the same time. The teacher will not understand the question properly. When she calls our name, we can ask questions, but calling every name in the class and clarifying the doubts in online sessions is very difficult. I miss the interaction with teachers in class' (Students 5, 17 and 20 highlighted). Student 8 expresses his concern for missing the peer academic discussion. 'In offline classes, we used to sit in groups and study. When there is any doubt in concepts, we use to discuss and help each other in understanding. But in an online class, it is not possible. I miss the peer discussion badly' - Student 
5 signifies his difficulty communicating in the real-time online environment. 'In online class hours, discussing with friends or clarifying doubts with the staff is very difficult for me.'

4. The problem of physical wellbeing

This theme deals with health problems caused by continuously attending online classes.

'My eyes are stressed out. I'm not used to attending online lectures before the pandemic. This is the first time for me to attend online classes. My online classes are about four to five hours daily. Continuously watching the mobile screen for hours together, my eyes are stressed out. I'm getting headaches and neck pain as well. These online classes are very difficult for me." (Students 10, 13 and 18 mentioned). 'I am feeling uncomfortable with the learning posture, sitting all day in front of the mobile phone or laptop is very difficult. I feel numb. At night I could not sleep properly.' (Students 11, 13 are 17 are prevalent).

5. The distractions inherent with the medium

This theme concerns the distractions because of the internet like unwanted advertisements and pop-up games on the internet.

'I attend online classes conducted by school teachers. When I cannot attend the class, or when I have double in some concepts, in self-interest I watch videos online. The advertisements that pop up during online lessons are disturbing, and it deviates my thinking process' (Students 3, 5, 9 and 14 have mentioned). Students 8 and 9 said their problems with pop up games in between the online classes. 'When I watch videos online, to clarify doubts, many game ads pop up and distract me.'

\section{Digital illiteracy}

This theme discusses the inability of the rural students and their parents in using technological apparatus. The lack of Information and communication skills prevents them from using the internet.

'I don't know how to join in online classes. I hadn't heard about online education before the pandemic. Online classes are very new to me. I need external help in starting the classes. Even in class, I don't know how to operate the interface. Online classes are challenging for me' (Students 6, 8 said in common). Student 20 discussed her problem with using devices. She is a firsttime user of a smartphone, and she didn't know how to use it properly. 'My teacher usually sends pdf and modules for learning. But I don't know how to use the smartphone and access those materials. In my home also no one can support me in technical issues. It is very difficult for me to study online.' 
$R Q 2$. The suggestions of rural students for the betterment of online education.

Interviewees discussed three significant suggestions for the betterment of their online education.

1. Providing appropriate technological infrastructure

Most of the participants opinionated that they need proper technological infrastructure for pursuing their education.

'I need a laptop that works smoothly' (Students 4, 8). 'I need a mobile phone and a good internet connection' (Students 9, 19) are frequent. Student 10 discusses her need for a sound mobile network for pursuing online education. Few students could not afford a mobile phone or laptop. They said, 'During the time of the pandemic it was very difficult for me and my friends to attend online lectures. Few people who are pursuing higher education or who are working in the field of education volunteered and extended their support. They gave us their laptops and mobile phones to attend the online education. They arranged the availability of the gadgets class wise. If one volunteer takes care of class eight students in the locality, others would help the class ninth students and so on. This is how we study through online education.' All the students who couldn't attend online classes said, 'I couldn't attend the scheduled online classes regularly due to various reasons. So my class teacher has created a WhatsApp group and she uses it to send pdf and modules so that those who miss the online class can make use of the notes.'

\section{Facilitating technical assistance}

Most of the participants observed that they need technical assistance in online education. Narratives like 'I need someone who can help me connect to the online classes' (Student 12). 'I need some external support if my device gets hanged' (Student 3) is common. Student 15 discusses providing a facilitator to take care of online education for every class.

\section{Providing a convenient academic atmosphere}

Most participants reckoned that they need a proper academic atmosphere for studying. Attending online classes at home is not possible in rural areas. Most of the students stated that 'I could not attend online class because of poor bandwidth in my locality,' 'no proper study atmosphere at home,' 'parents could not afford us a laptop or mobile phone or tablet to attend an online class.' Student 11 viewed that providing a library and reading rooms in each village can help to solve the problem. 'If there is any common study area for the students in rural areas, like a library, study centres, we can concentrate on academics very well.' 


\section{Discussion}

The goal of the present study was to identify the problems faced by rural students in accessing the online education and to find out the suggestions of students regarding the betterment of online education. The current study identified six major problems of rural students in online education: inadequate technology, unacquainted academic atmosphere, digital disconnect, the problem of physical wellbeing, the distractions inherent with the medium, digital illiteracy.

Among these six problems, digital illiteracy, inadequate technology and digital disconnect are directly related to the issue of digital inequality ('The digital divide information, people, and technology,' n.d.). Rural students are not equipped with proper devices, and they lack basic connectivity. These technological imbalances lead to the concept of the knowledge gap, information-rich and information poor (Gaillard, 2001). As Pearson (2002) study says, the information-rich have access to modern technologies, proper connectivity, and they know how to use the technologies and get the information required to them. Still, the poor do not have access to modern technologies, and they lack basic connectivity. Therefore, they are unable to get the information they want. Knowledge gap can provide severe imbalances in the information reach between the affluent urban students and the rural students. Therefore, it is crucial to address these issues.

Peña-López (2010) mentioned that beyond attitudes, there is a whole constellation of strategic digital competences that are most needed. Only with the help of digital competencies, the mix of ICTs in education can have an impact, both in terms of digital literacy and in terms of academic performance. The present study findings state that, among other matters, an unacquainted academic atmosphere may hinder the free flow of educational information to rural students. It will have severe implications in the students' education and knowledge gathering process. Other issues like the problem of physical wellbeing and the distractions inherent with the medium are also important because of the far-reaching consequence of these issues in the rural school students' education. Our study also proposed three suggestions from the rural students for the betterment of their education, providing appropriate technological infrastructure, facilitating technical assistance and providing a convenient academic atmosphere. Providing proper infrastructure and technology in rural areas helps not only the rural students but also a larger rural community. Facilitating technical assistance to the students can be a good practice since rural students are new to the online education scenario. Rural students and their parents should be given technical assistance in accessing online education. Rural students can be facilitated with a convenient academic atmosphere by 
arranging the classes in local libraries and reading rooms. This will not only help them to concentrate on their studies but also help to build a habit of reading.

\section{Conclusion}

After the outbreak of the COVID-19 pandemic, the academic institutions in the country have shifted to the online mode of teaching. The shift from the traditional method to the online method of teaching has created many problems in both the teaching community and the student community. Twenty interviews have been conducted with the rural school students to find out their problems in accessing online education and to find out their proposed solutions. All the respondents reported at least one sort of technological inadequacy while accessing online classes. Inadequate technology includes poor internet connectivity, lack of gadgets like mobiles phones or laptops. The next problem is the unacquainted academic atmosphere while attending online classes. Almost all the respondents are attending online classes from their homes, but they lack a proper study atmosphere. The respondents lack concentration due to the noisy atmosphere and they would be interrupted by the family members in between the online class hours. The next issue is digital disconnect. Most of the respondents have reported that they lack peer discussion, unable to grasp concepts, difficulty in clarifying doubts, and difficulty in communicating in real-time interaction. The next concern is the problem of physical wellbeing. Respondents are having various health issues caused by continuous online classes. The distractions inherent with the medium is the next problem faced by the respondents. Unwanted advertisements, pop-ups, game ads and other ads irrelevant to academics are disturbing the students. Then comes the problem of digital illiteracy. Most of the respondents are first time users of smartphones or laptops. They lack the information and communication skills that are required to access online education. These are identified as the major problems faced by rural school students during online education. Due to the above-mentioned issues, the students are finding it difficult to keep pace with online classes. The respondents proposed a few solutions to the problems. They need proper infrastructure and technology to attend online education. Most of the rural areas in India are ill-equipped with technological infrastructure. They are facing digital disconnect, due to which they are excluded from the digital world. The students also lack technical assistance and sufficient technical knowledge to attend online education. The problem of digital illiteracy also excludes the students from the digital world. There should be proper training sections for the students in using 
and accessing online education services. The students should also be facilitated with proper technical assistance and a suitable academic atmosphere to mitigate their problems in online education. The problems of the rural students in attending online education have to be looked upon and have to be resolved. The involvement of civil society in providing the digital infrastructure to rural students will help to bridge the gap of digital divide, since today's students are tomorrow's citizens who help for better prospects of the nation.

\section{References}

ABOAGYE, E., YAWSON, J. A., \& APPIAH, K. N. (2020). COVID-19 and E-learning: The challenges of students in tertiary institutions. Social Education Research, 1-8.

ADEDOYIN, O. B., \& SOYKAN, E. (2020). COVID-19 pandemic and online learning: The challenges and opportunities. Interactive Learning Environments. Available from:_https://doi.org/10.1080/10494820.2020.1813180

ALMAZOVA, N., KRYLOVA, E., RUBTSOVA, A., \& ODINOKAYA, M. (2020). Challenges and opportunities for Russian higher education amid COVID-19: Teachers' perspective. Education Sciences, 10(12).

ASWATHI, P. \& MOHAMED HANEEFA K. (2020). Attitude towards information technology and digital divide: A study among students in universities in Kerala, India. Library Philosophy and Practice, 4437.

AYDIN, M. (2020). Does the digital divide matter? Factors and conditions that promote ICT Literacy. Telematics and Informatics, 101536.

BAMEZAI, G., ROY, A., ROY, AN., CHHETRI, S. (2020). Gender mainstreaming as an essential part of journalism education in India. World of Media. Journal of Russian Media and Journalism Studies, 3, pp. 5-33. DOI: 10.30547/worldofmedia.3.2020.1

CARVIN, A. (2000). More than just access: Fitting literacy and content into the digital divide equation. Educause Review, 35(6), pp. 38-47.

CRONIN, B. (2002). The digital divide. Library Journal, 127(3).

DELAVARRE, C., IRVIN, M. J., JORDAN, A. W., HANNUM, W. H., \& FARMER, T. W. (2014). Reasons for student dropout in an online course in a rural $\mathrm{K}-12$ setting. Distance Education, 35(3), pp. 324-344. Available from: https://doi.org/10.1080/ 01587919.2015.955259

EMMANUEL, G. (2020). Tamil Nadu: 14-year-old dies by suicide after father could not buy smartphone for online classes. Bangalore Mirror, 1st August, 2020. Available from: https://bangaloremirror.indiatimes.com/news/india/tamil-nadu14-year-old-dies-by-suicide-after-father-could-not-buy-smartphone-for-onlineclasses/articleshow/77303306.cms 
GAILLARD, F. D. (2001). Understanding the digital divide as it relates to electronic commerce. Unpublished doctoral dissertation, Old Dominion University.

GAURAV, K. (2020). Magnitude and determinants of digital divide among the users of online education in Kerala. Dogo Rangsang Research Journal, 10(6), pp. 259-266.

GLADKOVA, A., VARTANOVA, E., \& RAGNEDDA, M. (2020). Digital divide and digital capital in multiethnic Russian society. Journal of Multicultural Discourses, 15(2), pp. 126-147. DOI: 10.1080/17447143.2020.1745212

GONZÁLEZ-BETANCOR, S. M., LÓPEZ-PUIG, A. J., \& CARDENAL, M. E. (2021). Digital inequality at home. The school as compensatory agent. Computers and Education, 168(March). Available from: https://doi.org/10.1016/j. compedu.2021.104195

HARGITTAI, E. (2002). Second-level digital divide: Differences in people's online skills. First Monday, 7(4).

ISTANCE, D., \& REES, G. (1995). Lifelong learning in Wales: A programme for prosperity (NIACE Cymru policy discussion paper). Leicester, UK, NIACE.

JENA, P. K. (2020). Impact of pandemic COVID-19 on education in India. International Journal of Research in Commerce and Management, 5(10), pp. 7-11. Available from:_https://doi.org/10.24941/ijcr.39209.07.2020

KOH, J. H. L., \& KAN, R. Y. P. (2020). Students' use of learning management systems and desired e-learning experiences: Are they ready for next generation digital learning environments? Higher Education Research \& Development, 1-16.

KUMAR, P. (2020). Reference based study on impact of COVID-19 on education systems. International Journal of Current Research, 12(7), pp. 12582-12586.

LEMBANI, R., GUNTER, A., BREINES, M., \& DALU, M. T. B. (2020). The same course, different access: The digital divide between urban and rural distance education students in South Africa. Journal of Geography in Higher Education, 44(1), 70-84. https://doi.org/10.1080/03098265.2019.1694876

MAHMOOD, S. (2021). Instructional strategies for online teaching in COVID-19 pandemic. Hum Behav \& Emerg Tech, 3, pp. 199-203. Available from:_https://doi. org/10.1002/ Hbe2.218

MIROSHNICHENKO, I., MOROZOVA, E., \& MESHCHERYAKOVA, E. (2021). Policy for overcoming digital inequality: Structure, actors and technologies. Proceedings of the 6th International Conference on Economics, Management, Law and Education (EMLE 2020), 165, pp. 401-405. Available from: https://doi.org/ 10.2991/aebmr.k.210210.065

MISHRA, S. V. (2020). COVID-19, online teaching, and deepening digital divide in India. SocArXiv. Available from:_https://doi.org/10.31235/osf.io/wzrak 
MPUNGOSE, C. B. (2020). Are social media sites a platform for formal or informal learning? Students' experiences in institutions of higher education. International Journal of Higher Education, 9(5), pp. 300-311.

MUTHUPRASAD, T., AISWARYA, S, ADITYA, K. S., \& JHA, G. K. (2020). Students' perception and preference for online education in India during COVID-19 pandemic. SSRN Electronic Journal. Available from:_https://doi.org/10.2139/ ssrn.3596056

NGUYEN, M. H., HARGITTAI, E., \& MARLER, W. (2021). Digital inequality in communication during a time of physical distancing: The case of COVID-19. Computers in Human Behavior, 120. Available from: https://doi.org/10.1016/j. chb.2021.106717

NIEMINEN, H. (2016). Digital divide and beyond: What do we know of information and communications technology's long-term social effects? Some uncomfortable questions. European Journal of Communication, 31(1), pp. 19-32.

PEARSON, T. (2002) Falling behind: A technology crisis facing minority students. Tech Trends, 46(2), pp. 15-20.

PEÑA-LÓPEZ, I. (2010). From laptops to competences: Bridging the digital divide in education. RUSC. Universities and Knowledge Society Journal, 7(1), pp. 21-32.

PRENSKY, M. (2001a). Digital natives, digital immigrants. Part 2: Do they really think differently? On the horizon.

PRENSKY, M. \& BERRY, B. D. (2001b). Do they really think differently? On the horizon, 9(6), pp. 1-9.

PRENSKY, M. (2005). Engage me or enrage me. Educase Review, 40(5), pp. 61- 64.

PUMPTOW, M. \& BRAHM, T. (2020). Students' digital media self-efficacy and its importance for higher education institutions: Development and validation of a survey instrument. Technology, Knowledge and Learning. Available from:_https:// doi.org/10.1007/s10758-020-09463-5

RAGNEDDA, M. (2018) Conceptualizing digital capital. Telematics and Informatics, 35, pp. 2366-2375.

RAZA, S. A., KHAN, K. A., \& RAFI, S. T. (2020). Online education \& MOOCs: Teacher self-disclosure in online education and a mediating role of social presence. South Asian Journal of Management, 14(1), pp. 142-158.

SELWYN, N., GORARD, S., \& WILLIAMS, S. (2001). Digital divide or digital opportunity? The role of technology in overcoming social exclusion in US education. Educational Policy, 15(2), pp. 258-277.

SELWYN, N. \& FACER, K. (2007). Beyond the digital divide. Futurelab, UK. 
SINGH, V. \& THURMAN, A. (2019). How many ways can we define online learning? A systematic literature review of definitions of online learning (19882018). American Journal of Distance Education, 33(4), pp. 289-306. Available from: https://doi.org/10.1080/08923647.2019.1663082

TARMAN, B. (2003). The digital divide in education. Online submission, Paper presented at the Annual International Standing Conference for the History of Education (ISCHE XXV) (25th, Sao Palo, Brazil, Jul 2003).

TARTAVULEA, C. V., ALBU, C. N., ALBU, N., DIEACONESCU, R. I., \& PETRE, S. (2020). Online teaching practices and the effectiveness of the educational process in the wake of the COVID-19 pandemic. Amfiteatru Economic, 22(55), pp. 920-936.

The digital divide - information, people, and technology (n.d.). Available from: https://psu.pb.unizin.org/ist110/chapter/9-3-the-digital-divide/

TRAPPEL, J. (2019). Digital media inequalities: Policies against divides, distrust and discrimination. Nordicom.

ULLAH, M. S. (2020). ICTs, power prejudice and empowerment: Digital exclusion of the poor in rural Bangladesh. In: Digital inequalities in the global south, Palgrave Macmillan, Cham.

VAN DEURSEN, A. J. \& VAN DIJK, J. A. (2019). The first-level digital divide shifts from inequalities in physical access to inequalities in material access. New Media \& Society, 21(2), pp. 354-375.

VARTANOVA,E., GLADKOVA,A., LAPIN,D., SAMORODOVA,E., \&VIKHROVA, O. (2021). Theorizing Russian model of the digital divide. World of Media. Journal of Russian Media and Journalism Studies, 1, pp. 5-40. DOI: 10.30547/worldofmedia.1.2021.1

VISHKAIE, R. (2020). The pandemic, war, and sanctions: Building resilience for the digital divide in education. Interactions, 27(4), pp. 36-37.

VOLERY, T. \& LORD, D. (2000). Critical success factors in online education. International Journal of Educational Management, 14, pp. 216-223. DOI:10.1108/09513540010344731

WARSCHAUER, M. (2004). Technology and social inclusion: Rethinking the digital divide. MIT press.

ZULKARNAIN, Z., HELENI, S., \& THAHIR, M. (2020). Digital literacy skills of math students through e-learning in COVID-19 era: A case study in Universitas Riau. Journal of Physics: Conference Series, 1663(1). 